\title{
Correlation Between Transabdominal Sonographically Measured Prostate Volume with Anthropometric Factor in Normal Healthy Subjects
}

\author{
MONOWARA M ${ }^{\mathrm{a}}$, AHMED AU ${ }^{\mathrm{b}}$, MOHIUDDIN AS $^{\mathrm{c}}$, TAHER MA ${ }^{\mathrm{d}}$, NASRIN Z ${ }^{\mathrm{e}}$, HOSSAIN MM ${ }^{\mathrm{e}}$
}

\begin{abstract}
:
To investigate the relationship between total prostate volume with anthropometric factor like age, height, weight and BMI. This can be useful in assessing the normality of prostate gland. Method: In 42 normal healthy subjects the length, anteroposterior and transverse diameters of prostate gland were measured \& prostate volumes were calculated by using prolate ellipse formula. Age, height, weight of the subjects were recorded and body mass index calculated accordingly. Result: Correlation co-efficient or $r$ test was used to find out the relationship between the variables. $P$
\end{abstract}

\section{Introduction}

The prostate is a fibro muscular glandular organ which surrounds the proximal part of the male urethra. Anatomically prostate is divided into five lobes. Imaging

a. Dr. Mahmuda Monowara, M.Phil (Radiology \& imaging), Assistant Professor, Department of Radiology \& imaging, Dhaka Shishu Hospital, Sher-e-Bangla Nagor, Dhaka-1207, Bangladesh.

b. Prof. Dr. Akhter Uddin Ahmed, DMRD(Radiology \& imaging), Former Head of department,Departmant of Radiology \& imaging, BIRDEM General Hospital, Shahbag Dhaka-1000, Bangladesh.

c. Prof. Dr. Abu Saleh Mohiuddin, MD (Radiology \& imaging), Professor, Head of Department, Department of Radiology \& imaging, BIRDEM General Hospital, Shahbag Dhaka-1000, Bangladesh.

d. Dr. Mohammad Abu Taher, MD (Radiology \& imaging), Associate Professor, Department of Radiology \& imaging, BIRDEM General Hospital, Shahbag, Dhaka-1000, Bangladesh.

e. Dr. Zinat Nasrin, MD (Radiology \& imaging), Department of Radiology \& imaging, NIO, Sher-e-Bangla Nagor, Dhaka-1207, Bangladesh.

f. Dr. Mohammad Mahbub Hossain, M.Phil (Radiology \& imaging), Department of Radiology \& imaging, BIRDEM General Hospital.

Adress of correspondence: Dr. Mahmuda Monowara, Assistant Professor,Department of Radiology \& imaging, Dhaka Shishu Hospital, Sher-e-Bangla Nagor, Dhaka-1207, Bangladesh. Tel:88001676097932. Email: mahmuda085@yahoo.com

Received: September 10, $2011 \quad$ Accepted: December 22, 2011 value $<0.05$ was considered as statistically significant. Total prostatic volume correlation coefficient with age, weight and BMI were $0.907,0.883$ and $0.352(p<0.001)$ respectively, but no significant correlation $(r=0.133 ; p>0.05)$ was found between prostatic volume and height. Conclusion: Total prostate volume has a strong significant linear relationship \& age, weight \& BMI. But height does not correlate significantly with total prostate volume. Thus anthropometric factors like age, weight, BMI can therefore be used to predict prostate volume prior to ultrasound.

(Birdem Med J 2012; 2(1): 29-32)

of prostate by ultrasound, the organ is not depicted in terms of lobes but by zonal anatomy thus the central zone, peripheral zone and transition zone.

Normal prostate gland is a rather symmetric triangular or ellipsoid structure surrounded by bright echogenic peri prostatic fat. The urethra runs through the center. The end closest to the bladder is known as the base and the end nearest to the penis is called the apex. The area round the urethra is known as the central and transition zone. The glandular peripheral zone and central zone are light gray area based on multiple echogenic interfaces produced by gland wall. Thus the morphologic appearance of adult prostate gland consists of two well delineated regions with in the prostate rather than lobes. ${ }^{1-2}$

Trans abdominal ultrasound is an extremely important but available imaging method in the evaluation of the prostate volume to the fact that it is easy to use, provides real-time images, does not utilize radiation. In case of gross enlargement of prostate, confirmation of enlarge prostate is easy. In case, where there is only mild enlargement, making decision about the size can be difficult. The result of the study will help clinicians in assessing the normality of prostate size with regard to anthropometric variables. No study regarding normal 
prostate volume is carried out in our country, to the best of our knowledge.

\section{Materials and Methods}

Scope of study:

This cross sectional study was carried out in the Department of Radiology and Imaging, BIRDEM, Dhaka during the period of 1st June, 2009 to 30th May, 2010 , to find out correlation of transabdominal sonographically measured prostate volume in healthy adult male with anthropometric factor.

\section{Selection of the subjects}

Inclusion criteria:

- 30 to 45 years old healthy male subjects who came to the department for routine trans abdominal ultrasound.

\section{Exclusion criteria:}

Incidental diagnosis of any metabolic or other disease.

Sample size:

52 healthy adult male subjects were included in this study.

Consecutive 52 healthy subjects were taken for study, among them 10 were excluded due to incidental findings of metabolic disease. So, final sample size was 42 .

\section{Subject preparation:}

An informed consent was obtained from each participant. The subjects were referred to the department of radiology and imaging, BIRDEM for routine health checkup. After reviewing the clinical history, general examination of each subject was performed. Demographic data (age, body height, weight) of all subjects were collected at the time of physical examination. The body mass index (BMI) of each subject was calculated- BMI $=$ weight $(\mathrm{kg}) /$ height

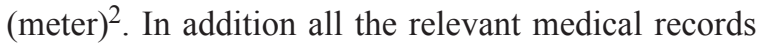
were checked to ensure that selected subjects had no pathological abnormalities. Initially selected subject of the study were 52 . Trans abdominal pelvic sonography was carried out on each subject in full bladder.

Choice of ultrasound machine and transducer Ultrasound machine

Siemens Sonoline Antares

Medisone Sono Ace 8000 Live
Transducer

3.5 Megahertz curvilinear transducer

Data collection and measurement:

Subjects were scanned in supine position. Scanning of the prostate was carried out with one of the departmental sonography equipment using $3.5 \mathrm{MH}_{Z}$ curvilinear probe. For better assessment the transducer is angled inferiorly under the symphysis pubis. Transverse sections are obtained at angulations of about $15^{0}$ toward the feet with the bladder full. The longitudinal imaging obtained, some time required application of suprapubic pressure.The length, anteroposterior, transverse diameters of the prostate were measured on frozen images. The prostate volume were estimated from the determine dimensions using the formula for prolate ellipse which is in corporated in the central processing unit of the ultrasound machine. ${ }^{3}$

Prostate ellipse

Prostate volume $=\left(\right.$ length $\times$ height $\times$ width $\left.\times\left[\frac{\pi}{6}\right]\right)$

Anteroposterior diameter $($ largest $)=$ height,

Transverse $=$ width,

Cephalo caudal $=$ length

\section{Anthropometric Measurements:}

Basic anthropometric measurements include those for body mass (weight), stature (height) and BMI. The procedure for taking the measurements is as illustrated by the following instructions for measuring height. The individual must stand straight against an upright surface, touching it with heels, buttocks, and back. The heels should be together and on the floor. It should be measured in meter. Weight should be taken in $\mathrm{kg}$. The BMI stands for Body Mass Index. It takes a person's weight in kilograms and divides it by their height in meters squared. The following table gives an indication of what BMI scores mean ${ }^{4}$

$\begin{array}{ll}\text { underweight } & <20 \\ \text { healthy range } & 20-24.9 \\ \text { overweight } & 25-29.9 \\ \text { obese } & >30 .\end{array}$

\section{Statistical analysis of data}

Statistical analysis of the results was done by computer software device as the statistical package for social science (SPSS) 12.0 windows. Correlation co-efficient 
or $r$ test was done to establish relationship between variables. The values were expressed as the percentage and mean \pm SE. P value $<0.05$ was considered as statistically significant.

\section{Result}

The mean of total prostate volume of the subjects was $23.3 \pm 3.5 \mathrm{ml}$ (range 16 to $28 \mathrm{ml}$.)The mean of weight was $73.5 \pm 1.73 \mathrm{~kg}$.(range 50 to $100 \mathrm{~kg}$ ), The mean of BMI was $26.7 \pm 0.58 \mathrm{~kg} / \mathrm{m}^{2}$ (range 20.5 to $34.7 \mathrm{~kg} / \mathrm{m}^{2}$ ). The mean of Height varied was $1.66 \pm 0.011 \mathrm{~m}$.(range 1.50 to $1.82 \mathrm{~m}$ ).

Total prostatic volume correlation coefficient with age, weight and BMI were 0.907, 0.883 and $0.352(p<0.001)$ respectively, but no significant correlation $(\mathrm{r}=0.133$; $\mathrm{p}>0.05$ ) was found between prostatic volume and height.

Table-I depict the mean values of anthropometric variables of the subjects.

\section{Table-I}

Values of anthropometric variables of the subjects

\begin{tabular}{lcccc} 
& $\begin{array}{c}\text { Age } \\
(\text { years })\end{array}$ & $\begin{array}{c}\text { Height } \\
(\mathrm{cm})\end{array}$ & $\begin{array}{c}\text { Weight } \\
(\mathrm{kg})\end{array}$ & $\begin{array}{c}\text { BMI } \\
\mathrm{kg} / \mathrm{m}^{2}\end{array}$ \\
\hline Range & $31-42$ & $1.50-1.82$ & $50-100$ & $20.5-34.7$ \\
Mean & 36.8 & 1.66 & 73.5 & 26.7 \\
Standard error & & 0.011 & 1.73 & 0.58 \\
\hline
\end{tabular}

Figure 1 is a scatter diagram of age against total prostate volume. This shows a general linear upward trend of total prostate volume with increasing age.

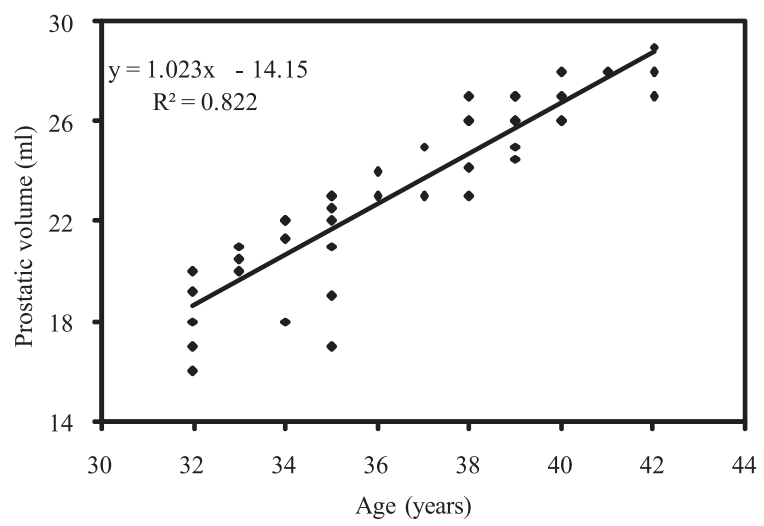

Fig-1: The scatter diagram shows significant relationship $(r=0.907)$ between prostatic volume and age.
Figure 2 is a scatter diagram of weight against total prostate volume. This shows a general linear upward trend of total prostate volume with increasing weight.

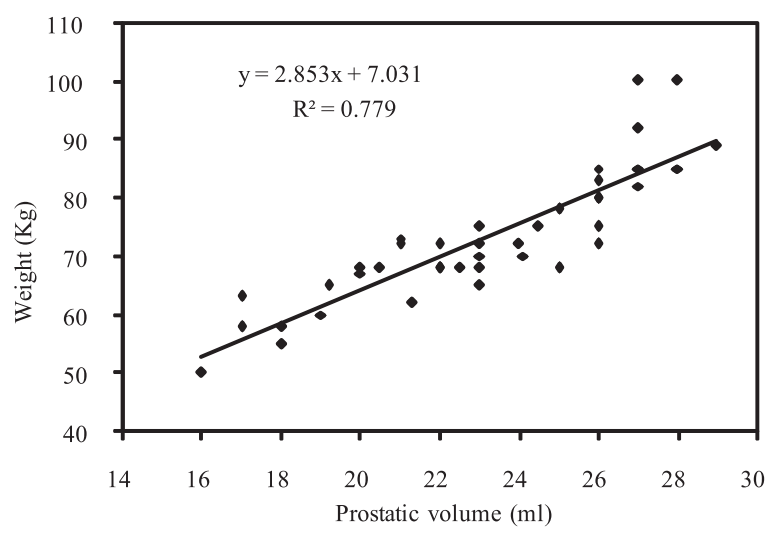

Fig.-2: The scatter diagram shows significant relationship $(r=0.883)$ between prostatic volume and weight.

Figure 3 is a scatter diagram of BMI against total prostate volume. This shows a general linear upward trend of total prostate volume with increasing BMI.

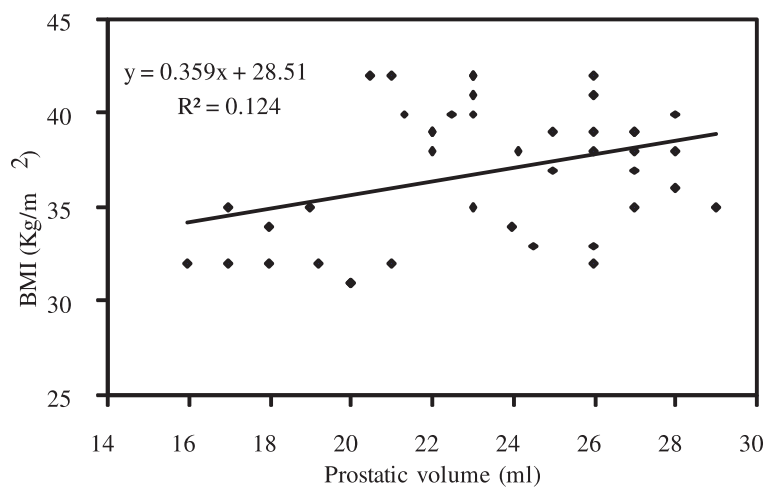

Fig.-3: The scatter diagram shows significant relationship $(r=0.352)$ between prostatic volume and BMI.

\section{Discussion:}

The result of the study showed a positive correlation between prostatic volume \& age, prostatic volume \& weight also between prostatic volume \& BMI, which is also statistically significant .But correlation between prostatic volume \& height was not statistically significant. 
This relationship between prostatic volume \& anthropometric factor like age, weight \& BMI should be put in clinical advantage. The uniqueness of this study is that it introduced new concepts, namely body mass index, height, weight along with age (30 to 45 years) in evaluation of prostate volume in normal healthy subjects. Prostate volume shows significant correlation with age, which is in agreement with the study of Ohagwu et al 2008..$^{5}$ There is also significant positive correlation between prostatic volume \& BMI. Lee et al $2006 \&$ Xie et al (2007) reported that prostatic volume was greater in obese than normal. ${ }^{6-7}$ Ochiai et al. (2005) reported that prostate volume was significantly correlated with age, body weight, body mass index, and BSA, but not with height which is an agreement with our study. ${ }^{8}$

The implication of the result of this study is that, in investigating patient prostate size, anthropometric factors like age, weight, BMI should be the primary consideration. There were some obvious shortcomings in our study. In determining the prostatic volume we used ellipsoid approximation (dimensional method) instead of the more accurate planimetric volumetry, although the dimensional method is used in our country for evaluation of prostate volume. Also measuring the height \& weight of the subjects may vary.

This study is purely feasibility in purpose and is not to be regarded as a chemical benchmark because of the small sample size \& predominance of overweight (one third) normal subject. We suggest a repeat study with much larger sample size to ascertain the accuracy of our findings.

\section{Conclusion:}

Total prostate volume has a strong significant linear relationship \& age. There is also significant correlation with weight \& BMI. But height does not correlate significantly with total prostate volume. Anthropometric factors like age, weight, BMI can therefore be used to predict prostate volume prior to ultrasound.

\section{References:}

1. McNeal. Regional morphology and pathology of the prostate. AM J Clin Pathology 1968; 49 : 347.

2. McNeal. Normal and pathologic anatomy of the prostate. Urology 1981; $17: 11$.

3. Sanders RC, and Casey J.Prostate: In Clinical Sonography edited by Sandars RC $2^{\text {nd }}$ ed. Little, Brown and Company Boston/Toronto/ London, 1991; p. 334

4. World Health Organization 1997, Obesity: Preventing and managing the global epidemic, Report of a WHO consultation on obesity, Geneva.

5. Ohagwu CC, Ugwu AC, Nwobi IC, \& Egwuanumku KI. Correlations between total prostate volume and anthropometric variables in normal subjects. Global Journal of Pure and Applied Sciences 2008; 14 : 213-5.

6. Lee S, Min HG, Choi SH, Kim YJ, Oh SW, Kim YJ, Park Y, Kim SS. Central obesity as a risk factor for prostatic hyperplasia. Obesity 2006; $14: 172-79$.

7. Xie LP, Bai Y, Zhang XZ, Zheng XY, Yao KS, Xu L, Zeegers MP. Obesity and benign prostatic enlargement: a large observational study in China. Urology 2007; 69: 680-4.

8. Ochiai A., Fritsche HA, Babaian RJ.Influence of anthropometric measurements, age and prostate volume on prostate-specific antigen levels in men with a low risk of prostate cancer. Urology 2005; 66: 819-23. 